\title{
Frequency of greatest temporary hearing threshold shift in harbor seals (Phoca vitulina) depends on fatiguing sound level
}

\author{
Ronald A. Kastelein ${ }^{\text {a) }}$ and Lean Helder-Hoek \\ Sea Mammal Research Company (SEAMARCO), Julianalaan 46, 3843 CC Harderwijk, The Netherlands \\ Robin Gransier \\ Department of Neurosciences, KU Leuven-University of Leuven, ExpORL, Herestraat 49, Box 721, \\ 3000 Leuven, Belgium
}

(Received 14 October 2018; revised 18 January 2019; accepted 11 February 2019; published online 13 March 2019)

\begin{abstract}
Harbor seals may suffer hearing loss due to intense sounds. After exposure for 60 min to a continuous $6.5 \mathrm{kHz}$ tone at sound pressure levels of 123-159 dB re $1 \mu \mathrm{Pa}$, resulting in sound exposure levels (SELs) of 159-195 dB re $1 \mu \mathrm{Pa}^{2}$ s, temporary threshold shifts (TTSs) in two harbor seals were quantified at the center frequency of the fatiguing sound $(6.5 \mathrm{kHz})$ and at 0.5 and 1.0 octaves above that frequency $(9.2$ and $13.0 \mathrm{kHz})$ by means of a psychoacoustic technique. Taking into account the different timing of post-exposure hearing tests, susceptibility to TTS was similar in both animals. The higher the SEL, the higher the TTS induced at frequencies above the fatiguing sound's center frequency. Below $\sim 179 \mathrm{~dB}$ re $1 \mu \mathrm{Pa}^{2} \mathrm{~s}$, the maximum TTS was at the center frequency $(6.5 \mathrm{kHz})$; above $\sim 179 \mathrm{~dB}$ re $1 \mu \mathrm{Pa}^{2}$ s, the maximum TTS was at half an octave above the center frequency $(9.2 \mathrm{kHz})$. These results should be considered when interpreting previous TTS studies, and when estimating ecological impacts of anthropogenic sound on the hearing and ecology of harbor seals. Based on the results of the present study and previous studies, harbor seal hearing, in the frequency range $2.5-6.5 \mathrm{kHz}$, appears to be approximately equally susceptible to TTS.
\end{abstract} (C) 2019 Acoustical Society of America. https://doi.org/10.1121/1.5092608

$[\mathrm{JJF}]$

Pages: $1353-1362$

\section{INTRODUCTION}

Marine mammals exposed to sufficiently intense sounds may suffer hearing loss, resulting in threshold shifts, which may be temporary (TTS; temporary threshold shift) or permanent (PTS; permanent threshold shift). A fatiguing sound's level, spectral content, temporal pattern, and duration may influence the threshold shift it causes and determine whether the shift is permanent or temporary (Melnick, 1991; Yost, 2007). The course and speed of recovery from a threshold shift depend on the sound to which an animal was exposed, the amount of shift incurred, and the species (e.g., Kastelein et al., 2013a; Houser et al., 2017). Generally, the greater the threshold shift, the longer the recovery period (Carder and Miller, 1972; Mills et al., 1979); if the shift is too large, complete recovery may not occur and the hearing ability of the animal may be reduced permanently (PTS). For the regulation and management of anthropogenic offshore activities that generate high levels of underwater sound (i.e., percussion pile driving, seismic surveys, sonars, detonations) it is important to know at what exposure sound pressure level (SPL) and durations PTS may be induced in different marine mammal species and for different sounds that are produced in areas in which the species occur. As it is not considered ethical to induce PTS in marine mammals, research on the onset and development of TTS is used to estimate the cumulative sound exposure level $\left(\mathrm{SEL}_{\mathrm{cum}}\right)$ that may lead to PTS.

${ }^{\text {a)} E l e c t r o n i c ~ m a i l: ~ r e s e a r c h t e a m @ z o n n e t . n l ~}$
Studies of TTS do not indicate the specific SELs at which PTS occurs, but are valuable in themselves. They give insight into effects of less harmful exposures, by providing TTS onset SEL, TTS growth rate, and critical levels. TTSs of various magnitudes and durations have the potential to compromise feeding, localization, communication, and predator detection, and may have negative effects on health and survival even if PTS does not occur. Pinnipeds are often active in murky water, during the night, and at depths where light hardly penetrates; they depend therefore to a large degree on sound and mechano-reception (via their whiskers), rather than on vision, for orientation and communication (Supin et al., 2001). Hearing damage may reduce the efficiency of these activities, thus reducing the animals' fitness, reproductive output and longevity. The ecological effect of reduced hearing depends not only on the magnitude of the threshold shift, its duration (which depends on the exposure duration plus the recovery time after exposure stops), but also on the hearing frequency range affected and the ecological importance of this frequency range for the animal.

Generally TTS is observed at frequencies higher than the center frequency of the fatiguing sound. It often occurs half an octave above the center frequency (McFadden, 1986), but at higher exposure levels it may affect a much wider bandwidth of hearing (Wang et al., 2002). This halfoctave phenomenon has been observed in marine mammals (Finneran, 2015). In terrestrial mammals, the hearing frequencies affected by fatiguing sound depend not only on the center frequency of the fatiguing sound, but also on the received SPL, as shown for guinea pigs (Cavia porcellus) by 
Cody and Johnstone (1981) and for humans by McFadden and Plattsmier (1983). Although several mechanisms have been hypothesized, the psychophysical origin of this frequency shift is not fully understood (Ramamoorthy and Nuttall, 2012). In marine mammals, the "received SPL-affected frequency" phenomenon in noise induced hearing loss studies has only been studied in a small odontocete species (the harbor porpoise, Phocoena phocoena) that was exposed to a continuous wave of $6.5 \mathrm{kHz}$ (Kastelein et al., 2014b).

It is important to know whether hearing frequencies affected by fatiguing sound also depend on the received SPL in pinnipeds. In this study, harbor seals (Phoca vitulina) were used. The harbor seal's wide distribution area in the coastal waters of the northern hemisphere (Burns, 2002) overlaps with areas in which noisy anthropogenic activities occur. The underwater sounds produced may cause TTS or PTS in harbor seals if the received SPL and/or exposure duration are high/ long enough. So far, only three studies have been conducted in which TTS due to underwater sounds was studied in harbor seals. After exposing a harbor seal to octave-band noise centered at $2.5 \mathrm{kHz}$, Kastak et al. (2005) tested its hearing at two frequencies $(2500$ and $3530 \mathrm{~Hz})$ and found that the highest TTS had occurred at the center frequency. After exposing two harbor seals to octave-band noise centered at $4 \mathrm{kHz}$, Kastelein et al. (2012) tested their hearing only at $4 \mathrm{kHz}$. After exposing two harbor seals to playbacks of pile-driving sound (the one third octave band centered at $630 \mathrm{~Hz}$ contained the most energy), Kastelein et al. (2018b) tested their hearing at 0.25 , $0.5,1,2,4,8,16$, and $32 \mathrm{kHz}$, and only found TTS at 4 and $8 \mathrm{kHz}$ (the highest TTS occurred at $4 \mathrm{kHz}$ ).

The limited information on TTS in harbor seals does not allow prediction of which hearing frequency needs to be measured after sound exposure, in order to detect the greatest sound-induced TTS. This information is required for setting safety criteria for underwater sounds, in order to prevent PTS in wild harbor seals. Underwater sound exposure limits should be based on changes across all hearing frequencies, and not just at the frequency at which the maximum TTS is detected. Hearing frequencies required for localization, prey detection, or communication may be important for health or survival, though they may not be the frequencies at which maximum TTS occurs. The duration of the TTS (i.e., the speed of recovery of hearing) is also an important factor to consider when evaluating the impact of a sound. Therefore, as a step towards testing susceptibility to TTS in the harbor seal's entire hearing range, the goals of the present study were to expose harbor seals to a $6.5 \mathrm{kHz}$ continuous pure tone and to quantify the TTS induced by the received SPL in the affected hearing frequencies. This will allow us to determine whether or not the hearing frequency that is most affected depends on the received SPL, and to gain insight into the process of hearing recovery in harbor seals that have been exposed to loud underwater sounds.

\section{MATERIALS AND METHODS}

\section{A. Study animals and study area}

The study animals were two female harbor seals, identified as harbor seals F01 and F02. During the study they were
$8-10 \mathrm{yr}$ old and the body mass of each was around $40 \mathrm{~kg}$ in summer and $65 \mathrm{~kg}$ in winter. The seals received most of their daily fish ration during hearing test sessions. They were healthy throughout the study, and had participated in eight previous hearing studies, which had shown that they had sensitive and very similar hearing (Kastelein et al., 2009a; Kastelein et al., 2009b; Kastelein et al., 2010a; Kastelein et al., 2012; Kastelein et al., 2013b; Kastelein et al., 2015b; Kastelein et al., 2018a; Kastelein et al., 2018b). Variation in the animals' performance was minimized by making weekly adjustments (usually in the order of $100 \mathrm{~g}$ ) to their daily food ration, based on their weight and performance during the previous week and the expected change in water and air temperatures in the following week.

The study was conducted at the SEAMARCO Research Institute, The Netherlands, in a remote and quiet location. The animals were kept, and the study was conducted, in an outdoor pool $(8 \mathrm{~m} \times 7 \mathrm{~m}, 2 \mathrm{~m}$ deep, with haul-out areas). The pool walls and the sandy bottom were covered with aquatic vegetation. Skimmers kept the water level constant so that sound conditions were stable. Seawater was pumped directly from the nearby Oosterschelde, a lagoon of the North Sea, into the water circulation system. Recirculation through biological and sand filters ensured year-round water clarity. The average monthly temperature varied during the study period between $0{ }^{\circ} \mathrm{C}$ and $22^{\circ} \mathrm{C}$ and the salinity was around $3.4 \%$. The water circulation system and the aeration system for the bio-filter were made as quiet as possible. During the sound exposure sessions, barriers were placed so that the seals could not leave the water. During the hearing tests, the seal not being tested was kept in the water next to the haul-out area and was asked to perform quiet behaviors to keep her occupied.

\section{B. Acoustics}

\section{SPL measurement equipment}

The ambient noise was measured, and the fatiguing sound and hearing test signals were calibrated, once every two months during the study period by an acoustic consulting agency (TNO). The sound measurement equipment consisted of three hydrophones [Brüel \& Kjaer (B\&K), Model No. 8106] with a multichannel high-frequency analyzer (B\&K PULSE, Model No. 3560 D), and a laptop computer with B\&K PULSE software (Labshop, version 12.1). The system was calibrated with a pistonphone (B\&K, Model No. 4223). The broadband sound pressure level (SPL; dB re $1 \mu \mathrm{Pa}$, ANSI, 2013) of each hearing test signal was derived from the $90 \%$ received energy flux density and the corresponding $90 \%$ time duration $\left(t_{90}\right)$ (Madsen, 2005). The SPL of the fatiguing sound was determined over a period of $10 \mathrm{~s}$.

\section{Ambient noise}

Great care was taken to make the harbor seals' listening environment as quiet as possible. Only researchers involved in the hearing tests were allowed within $15 \mathrm{~m}$ of the pool during hearing test sessions, and they were required to stand still. Under test conditions (water circulation system off, no rain, and wind force Beaufort 4 or below) the ambient noise 
in the pool was very low and fairly constant in amplitude (Fig. 1).

\section{Fatiguing sound}

A $6.5 \mathrm{kHz}$ continuous (i.e., $100 \%$ duty cycle) sinusoidal wave $(\mathrm{CW})$ without harmonics was used as the fatiguing sound (i.e., the sound intended to cause TTS). This sound was selected because it is within the frequency range of some naval active sonar systems. This digitally generated sound (WAV file, sample rate: $768 \mathrm{kHz}$ ) was played back by a laptop computer (Acer Aspire, Model No. 5750) with a program written in LabVIEW, to an external data acquisition card (National Instruments, Model No. USB 6229), the output of which could be controlled in $1 \mathrm{~dB}$ steps with the LabVIEW program. The output of the card went through a ground loop isolator and custom-built buffer to a custom-built passive low-pass filter set to $8 \mathrm{kHz}$, after which it went to a power amplifier (East \&West, Model No. LS5002) which drove the transducer (Lubell, Model No. LL1424HP) through an isolation transformer (Lubell, Model No. AC1424HP). The transducer was placed at the north-eastern end of the pool at $1.5 \mathrm{~m}$ depth. The linearity of the transmitter system producing the fatiguing sound was checked during each calibration, and was found to be consistent to $1 \mathrm{~dB}$ within a $42 \mathrm{~dB}$ range (overlapping the SPL range used in the study).

To determine the fatiguing sound's distribution in the pool, the SPL was measured at 34 locations (on a horizontal grid of $1.2 \mathrm{~m} \times 1.2 \mathrm{~m}$ ), at three depths per location on the grid (0.5, 1.0, and $1.5 \mathrm{~m}$ below the surface). To determine their acoustic dose, the seals were monitored during the fatiguing sound exposure periods, in terms of both their location in the pool and the position of their head (at the water surface or completely submerged). During exposure to the $6.5 \mathrm{kHz}$ tone, it was observed that the animals swam throughout the entire pool, at all depths. Therefore, the average received SPL $\left(\mathrm{SPL}_{\mathrm{av} . r e}\right)$ as experienced by the harbor seals was calculated as the energetic average of the SPL at all 102 individual measurement locations. There were only small differences in SPL per depth and per location, and no gradient existed in the

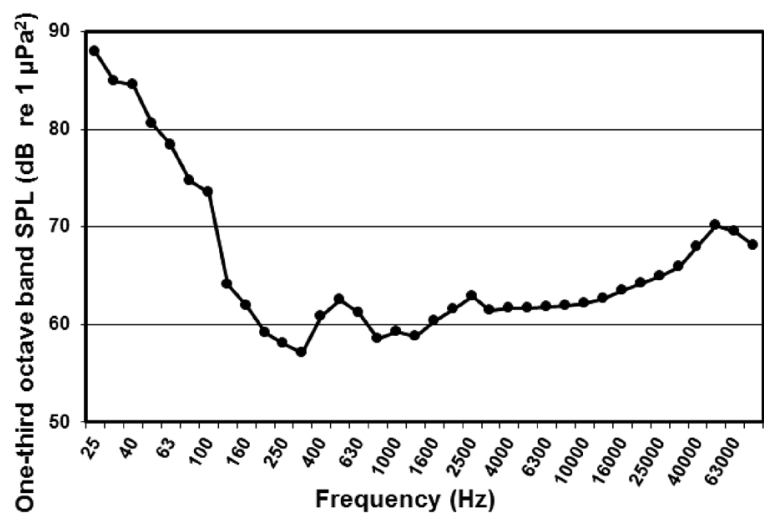

FIG. 1. Mean underwater ambient noise $(n=3)$ under test conditions (only researchers involved in the study within $15 \mathrm{~m}$ of the pool, water circulation system off, no rain, and wind force Beaufort 4 or below). Measurements were analyzed in one-third octave (base 10) bands. Above $\sim 10 \mathrm{kHz}$ the ambient noise was so low that it was dominated by the electronic noise of the measurement system.
SPL in relation to the distance to the transducer, resulting in a fairly homogeneous field (Fig. 2). The $6.5 \mathrm{kHz} \mathrm{CW}$ fatiguing sound was projected at various source levels, resulting in $\mathrm{SPLs}_{\text {av.re. }}$ ranging from 123 to $159 \mathrm{~dB}$ re $1 \mu \mathrm{Pa}$. For the $60 \mathrm{~min}$ exposure, the $\mathrm{SEL}_{\text {cum }}$, calculated as: $\mathrm{SPL}_{\mathrm{av} . \mathrm{re}}$. $+10 \log _{10}(60 \mathrm{~min} / 1 \mathrm{~s})$, ranged from 159 to $195 \mathrm{~dB}$ re $1 \mu \mathrm{Pa}^{2} \mathrm{~s}$.

Before each sound exposure test, the voltage output of the emitting system to the transducer and the voltage output of the sound-receiving system were checked with an oscilloscope (Dynatek-8300) and a voltmeter (Agilent-34401A), by producing a $6.5 \mathrm{kHz}$ continuous tone from the laptop. The acoustic underwater signal was checked with a hydrophone (B\&K 8101), a pre-amplifier (B\&K 2365) and a spectrum analyzer (Velleman-PCSU1000). If the values obtained were the same as those obtained during the SPL calibrations by the acoustic consulting agency, the SPLs were assumed to be correct, and a sound exposure test could be performed.

\section{Hearing test signals}

The harbor seals were trained to detect signals presented during hearing tests before and after exposure to the

\begin{tabular}{|c|c|c|c|c|c|}
\hline 0.5 m depth & & & & \\
\hline 153 & 154 & 146 & 146 & 149 & 160 \\
\hline 146 & 147 & 156 & $\mathrm{X}$ & $\mathrm{X}$ & 155 \\
\hline 147 & 153 & 147 & 149 & 153 & 162 \\
\hline 150 & 144 & 149 & 153 & 149 & 151 \\
\hline 146 & 147 & 153 & 155 & 149 & 157 \\
\hline 153 & 153 & 152 & 148 & 149 & 155 \\
\hline $1.0 \mathrm{~m}$ depth & & & & \\
\hline 144 & 146 & 151 & 152 & 156 & 151 \\
\hline 147 & 156 & 154 & $\mathrm{X}$ & $\mathrm{X}$ & 158 \\
\hline 149 & 149 & 152 & 149 & 147 & 150 \\
\hline 151 & 146 & 147 & 151 & 149 & 153 \\
\hline 139 & 145 & 146 & 149 & 149 & 153 \\
\hline 152 & 149 & 148 & 148 & 149 & 152 \\
\hline $1.5 \mathrm{~m}$ depth (depth of transducer) \\
\hline 147 & 153 & 159 & 158 & 158 & 159 \\
\hline 153 & 152 & 157 & $\mathrm{X}$ & $\mathrm{X}$ & 158 \\
\hline 148 & 144 & 146 & 154 & 154 & 152 \\
\hline 147 & 144 & 156 & 150 & 154 & 161 \\
\hline 147 & 152 & 152 & 155 & 151 & 158 \\
\hline 153 & 148 & 158 & 155 & 151 & 154 \\
\hline \multicolumn{5}{|c|}{} \\
\hline
\end{tabular}

FIG. 2. The SPL distribution in the outdoor pool when the $6.5 \mathrm{kHz} \mathrm{CW}$, used as the fatiguing sound, was being played (102 measurement locations: 34 locations, three per depth). Per location, the SPL did not vary systematically with depth. These data were used to calculate the average received SPL (SPL $\mathrm{Sv}_{\text {av.re. }}$ ) that the harbor seals experienced during sound exposures (SPL ${ }_{\text {av.re. }}$ shown: $153 \mathrm{~dB}$ re $1 \mu \mathrm{Pa}$; SD: $\pm 5 \mathrm{~dB} ; \mathrm{n}=102$ ). The two boxes with an $\mathrm{X}$ represent the location of the floating haul-out area; the black dot represents the location of the transducer at $1.5 \mathrm{~m}$ depth. 
fatiguing sound. Narrow band up-sweeps (linear frequencymodulated tones) were used as hearing test signals instead of pure tones, because sweeps lead to more stable received SPLs at the listening station (Finneran and Schlundt, 2007) and thus to more stable thresholds. For TTS studies, precise hearing thresholds are very important, as sometimes only small threshold shifts occur and study animals recover rapidly (Kastelein et al., 2012). The hearing test signals were generated digitally (Adobe Audition, version 3.0). The linear up-sweeps started and ended at $\pm 2.5 \%$ of the center frequency, and had durations of $1 \mathrm{~s}$, including a linear rise and fall in amplitude of $50 \mathrm{~ms}$. The WAV files used as hearing test signals were played on a laptop computer (Acer Aspire 5750 Model P5WEO) with a program written in LabVIEW, to an external data acquisition card (National Instruments, Model No. USB6229); the output was controlled in $1 \mathrm{~dB}$ steps with the LabVIEW program. The output of the card went through a ground-loop isolator and a custom-built passive low-pass filter and drove a balanced tonpilz piezoelectric acoustic transducer (Lubell, Model No. LL916) through an isolation transformer (Lubell, Model No. AC202). The SPL in the water at the location of a harbor seal's head while it was at the listening station was varied by the operator in $2 \mathrm{~dB}$ increments.

The hearing thresholds were tested at the frequency of the fatiguing sound $(6.5 \mathrm{kHz})$, half an octave above the frequency of the fatiguing sound $(9.2 \mathrm{kHz})$, and one octave above the frequency of the fatiguing sound $(13 \mathrm{kHz}$; limited sample size).

The received SPL of each hearing test signal was measured at the position of the harbor seal's head during the hearing tests. The calibration measurements were conducted with two hydrophones, one at the location of each auditory meatus of the harbor seal when it was positioned at the listening station. The linearity of the transmitter system was checked during each calibration and was found to be consistent to $1 \mathrm{~dB}$ within a $30 \mathrm{~dB}$ range (from $10 \mathrm{~dB}$ above the hearing threshold). The SPL at the two locations differed by $0-2 \mathrm{~dB}$, depending on the test frequency. The mean SPL of the two hydrophones was used to calculate the stimulus level during hearing threshold tests.

\section{Experimental procedures}

Each hearing test trial began with one of the harbor seals at the start/response buoy. The level of the hearing test sweep used in the first trial of the session was approximately $6 \mathrm{~dB}$ above the hearing threshold determined during the previous pre-exposure or post-exposure session. The harbor seals were trained to swim from the start/response buoy to the listening station in response to a hand signal from the trainer. The methodology was as described by Kastelein et al. (2012). The signal level was varied according to the one-up one-down adaptive staircase method (Cornsweet, 1962); 2 dB steps were used. This conventional psychometric technique (Robinson and Watson, 1973) produces a 50\% correct detection threshold (Levitt, 1971). A switch from a test signal level that the harbor seal responded to (a hit), to a level that she did not respond to (a miss), and vice versa, was called a reversal. Signals were produced at a random time 4-12 s after a seal stationed at the start/response buoy.

Each hearing test session consisted of $\sim 25$ trials and lasted for up to $12 \mathrm{~min}$ per animal (the first session after the fatiguing sound stopped was divided into three periods: $1-4$, 4-8, and 8-12 min). Sessions consisted of two thirds signalpresent and one third signal-absent trials, offered in quasirandom order (never more than three consecutive signalpresent or signal-absent trials).

One total sound exposure test, consisting of (1) preexposure hearing test, (2) fatiguing sound exposure, and (3) post-sound exposure (PSE) hearing test or tests, was conducted per day, starting at $0830 \mathrm{~h}$. The SPL of the sound during the fatiguing sound exposure period was increased slowly during the first $60 \mathrm{~s}$, to avoid startle responses, which may have led to large changes in the seals' swimming pattern. To see whether the seals selected particular locations in the pool during sound exposures, their surfacing locations were recorded on video and the operator watched their behavior on a monitor in the research cabin. The PSE hearing test (using the same sweep as used in the pre-exposure hearing test) commenced within 1 min after the fatiguing sound had stopped for F02, and 12 min after the sound had stopped for F01.

The two seals were always tested in the same order (to ensure a quick and efficient start after sound exposure stopped): first seal F02, then seal F01. In order to protect their hearing, the study animals could only be exposed to fatiguing sounds once per day, and randomizing the order in which they were tested, while maintaining the sample sizes, would have doubled the study period.

To gain insight into the duration of the TTS, not only the magnitude of TTS immediately after the exposure was recorded, but also the subsequent hearing recovery. The hearing sensitivity of seal F02 was tested during up to six PSE periods: 1-4 ( $\left.\mathrm{PSE}_{1-4}\right), 4-8$ ( $\left.\mathrm{PSE}_{4-8}\right), 8-12$ ( $\left.\mathrm{PSE}_{8-12}\right), 60$ (PSE 60 ), $120\left(\mathrm{PSE}_{120}\right)$, and $1440\left(\mathrm{PSE}_{1440}\right) \mathrm{min}$ after the fatiguing sound exposure ended. The hearing of seal F01 was tested 12-16 ( $\left.\mathrm{PSE}_{12-16}\right), 16-20$ ( $\left.\mathrm{PSE}_{16-20}\right), 20-24\left(\mathrm{PSE}_{20-24}\right), 72$ $\left(\mathrm{PSE}_{72}\right), 132\left(\mathrm{PSE}_{132}\right), 252\left(\mathrm{PSE}_{252}\right)$, and $1200\left(\mathrm{PSE}_{1200}\right) \mathrm{min}$ after the fatiguing sound exposure ended.

TTS was quantified for three hearing test sweeps (centered at $6.5,9.2,13 \mathrm{kHz}$ ). Sample sizes were chosen to maximize the time available for testing SPLs in which TTS seemed to occur, while minimizing the risk of hearing damage (from repeated exposure to the loudest sounds) and avoiding repeated testing of SPLs for which it was clear without analysis that TTS did not occur. As a precaution, sound exposure tests were not conducted on days after the seals had been exposed to the three highest SPLs.

Control tests were conducted in the same way as sound exposure tests, but without fatiguing sound exposure. Each control test started with a pre-exposure hearing test session (test signals centered at $6.5,9.2,13 \mathrm{kHz}$ ), but was followed by exposure to the normal (very low) ambient noise in the outdoor pool for $60 \mathrm{~min}$ (Fig. 1). The post-ambient exposure (PAE) hearing test session was divided into four periods: 1-4 $\left(\mathrm{PAE}_{1-4}\right), 4-8 \quad\left(\mathrm{PAE}_{4-8}\right), 8-12 \quad\left(\mathrm{PAE}_{8-12}\right)$, and 60 $\left(\mathrm{PAE}_{60}\right) \mathrm{min}$ after ambient noise exposure for seal F02, and 12-16 (PAE $\left.{ }_{12-16}\right), 16-20\left(\mathrm{PAE}_{16-20}\right), 20-24\left(\mathrm{PAE}_{20-24}\right)$, and 
$72\left(\mathrm{PAE}_{72}\right)$ min after ambient noise exposure for seal F01. The PAE test sessions had the same durations as preexposure hearing test sessions. Control tests were randomly dispersed during the study period among the fatiguing sound exposure tests, and also started at around $0830 \mathrm{~h}$. Data were collected between July 2014 and March 2017.

\section{Data collection and analysis}

The percentage of time that the seals spent with their heads at the water surface (nose in the air, mandible and lower part of skull under water) and with their head completely submerged was quantified from the video recordings, by using stopwatches. Because this analysis was very time-consuming it was conducted only on a sample of the sessions; for each $\mathrm{SPL}_{\mathrm{av} . \mathrm{re}}$, one to nine $60 \mathrm{~min}$ fatiguing sound exposures were randomly selected for analysis (the number varied, as the number of times each $\mathrm{SPL}_{\text {av.re. }}$ was tested varied). The seals could not always be distinguished from each other from the video recordings, so the data were pooled. Via a grid on the monitor screen, the pool was divided into 34 approximately $1.2 \times 1.3 \mathrm{~m}$ rectangles. The grid location of the seals was recorded every $5 \mathrm{~s}$.

The pre-exposure mean 50\% hearing threshold for each hearing test session $\left(\mathrm{PE}_{50 \%}\right)$ was determined by calculating the mean SPL of all reversal pairs in the pre-exposure hearing session. Only pre-exposure sessions with at least 10 reversals were included in the analysis. The TTS quantified in seal F02 1-4 min after sound exposure stopped $\left(\mathrm{TTS}_{1-4}\right)$, for each hearing test frequency, was calculated by subtracting the mean 50\% hearing threshold obtained during the $\mathrm{PE}_{50 \%}$ from the mean $50 \%$ hearing thresholds during $\mathrm{PSE}_{1-4}$. A similar method was used to calculate TTS $_{12-16}$ for seal F01.

We define the onset of TTS as occurring at the lowest $\mathrm{SEL}_{\text {cum }}$ at which a statistically significant difference could be detected between the hearing threshold shift due to the fatiguing sound exposures and the hearing threshold shift as measured after the control exposures (this shift was close to zero). When the sample size was 1 or 2 , we compared the hearing threshold to the control level without statistical analysis in order to judge whether TTS occurred or not. For larger sample sizes, the level of significance was established by conducting a one-way analysis of variance (ANOVA) on the TTS, separately for each seal and for each hearing test frequency, with the factor SPL (including zero as the control). When the ANOVA produced a significant value overall, the levels were compared to the control by means of Dunnett multiple comparisons. All analysis was conducted in Minitab 18, and data conformed to the assumptions of the tests used (Zar, 1999).

\section{RESULTS}

\section{A. Swimming pattern}

During the $60 \mathrm{~min}$ control sessions (only ambient noise), the seals spent $\sim 20 \%$ of their time with their heads at the water surface, and thus $\sim 80 \%$ of their time with their heads completely submerged. On a few occasions per session they raised their heads fully above the water surface for up to $2 \mathrm{~s}$. During $60 \mathrm{~min}$ exposures to the continuous $6.5 \mathrm{kHz}$ tone, the
TABLE I. The mean percentage of time the two harbor seals spent with their heads at the water surface during control sessions with ambient noise only, and during exposure to a continuous $6.5 \mathrm{kHz}$ tone at 7 SELs; $\mathrm{SD}=$ standard deviation. The remainder of the time was spent with their heads completely submerged.

\begin{tabular}{lccc}
\hline \hline $\begin{array}{l}\text { Exposure SEL } \\
\left(\mathrm{dB} \mathrm{re} 1 \mu \mathrm{Pa}^{2} \mathrm{~s}\right)\end{array}$ & $\begin{array}{c}\text { Mean \% of time with headat } \\
\text { the water surface }\end{array}$ & $\mathrm{SD}$ & $\mathrm{n}$ \\
\hline 0 (control) & 20 & 11 & 9 \\
159 & 28 & - & 1 \\
165 & 28 & 4 & 4 \\
171 & 27 & 6 & 9 \\
177 & 28 & 5 & 8 \\
183 & 31 & 6 & 9 \\
189 & 42 & 8 & 9 \\
195 & 39 & 11 & 7 \\
\hline \hline
\end{tabular}

time the seals spent with their heads at the water surface depended on the SEL (Table I). They spent $\sim 30 \%$ of their time with their heads at the water surface when the $\mathrm{SEL}=159-183 \mathrm{~dB}$ re $1 \mu \mathrm{Pa}^{2} \mathrm{~s}$. At and above $189 \mathrm{~dB}$ re $1 \mu \mathrm{Pa}^{2} \mathrm{~s}$, they spent $\sim 40 \%$ of the time with their heads at the water surface. During the control and exposure sessions, the seals used most of the pool, and did not specifically avoid the location of the transducer.

\section{B. Pre-stimulus response rate}

After the $60 \mathrm{~min}$ sound exposure periods, the seals were always willing to participate in the hearing tests. The prestimulus response rates for both signal-present and signal-absent trials (in the latter, the whistle was the stimulus, indicating

TABLE II. The harbor seals' pre-stimulus response rate in hearing test sessions (calculated from responses before the hearing test signal in signalpresent trials and responses before the whistle was blown in signal-absent trials) during the pre-exposure period, after exposure for $60 \mathrm{~min}$ to a continuous ( $100 \%$ duty cycle) $6.5 \mathrm{kHz}$ tone (the fatiguing sound), and after exposure for $60 \mathrm{~min}$ to low-amplitude ambient noise (control). All exposure SPLs and hearing test frequencies were pooled for the calculation of percentages. Seal F02's hearing tests began immediately after the end of the exposure periods (fatiguing sound or control), whereas seal F01's hearing tests began $12 \mathrm{~min}$ after the end of the exposure periods. Sample size $=$ the number of trials within hearing tests. PSE $=$ post sound exposure. PAE $=$ post ambient noise exposure.

Pre-stimulus response rate

\section{Seal F02}

\begin{tabular}{lccccc} 
Fatiguing sound & Pre-exposure & $\mathrm{PSE}_{1-4}$ & $\mathrm{PSE}_{4-8}$ & $\mathrm{PSE}_{8-12}$ & $\mathrm{PSE}_{60}$ \\
& $6.6 \%$ & $6.3 \%$ & $8.4 \%$ & $6.1 \%$ & $5.3 \%$ \\
Sample size & 1763 & 727 & 742 & 686 & 1628 \\
Control & Pre-exposure & $\mathrm{PAE}_{1-4}$ & $\mathrm{PAE}_{4-8}$ & $\mathrm{PAE}_{8-12}$ & $\mathrm{PAE}_{60}$ \\
& $6.5 \%$ & $10.3 \%$ & $7.4 \%$ & $13.5 \%$ & $5.6 \%$ \\
Sample size & 492 & 224 & 216 & 200 & 497 \\
Seal F01 & & & & & \\
Fatiguing sound & Pre-exposure & $\mathrm{PSE}_{12-16}$ & $\mathrm{PSE}_{16-20}$ & $\mathrm{PSE}_{20-24}$ & $\mathrm{PSE}_{72}$ \\
& $4.7 \%$ & $4.2 \%$ & $5.4 \%$ & $5.0 \%$ & $3.5 \%$ \\
Sample size & 1630 & 734 & 687 & 700 & 1371 \\
Control & Pre-exposure & $\mathrm{PAE}_{12-16}$ & $\mathrm{PAE}_{16-20}$ & $\mathrm{PAE}_{20-24}$ & $\mathrm{PAE}_{72}$ \\
& $4.7 \%$ & $6.9 \%$ & $5.7 \%$ & $5.2 \%$ & $3.4 \%$ \\
Sample size & 473 & 202 & 194 & 194 & 435 \\
\hline \hline
\end{tabular}


TABLE III. Mean ( \pm SD) initial TTS (in dB; TTS $_{1-4}$ in harbor seal F02 and TTS ${ }_{12-16}$ in seal F01) after exposure to a continuous 6.5 kHz tone at several SELs for $60 \mathrm{~min}$, quantified at hearing frequencies $6.5,9.2$, and $13 \mathrm{kHz}$ (i.e., at $0,0.5$, and 1 octave above the frequency of the fatiguing sound). Results from the control sessions are shown in bold (no TTS occurred); $\mathrm{n}=$ sample size, * TTS significantly different from control value, ${ }^{\text {NS }}$ TTS not significantly different from control value, ${ }^{\mathrm{AS}}$ (assumed similar): no analysis carried out, but TTS assumed to be similar to control value, and ${ }^{\mathrm{AD}}$ (assumed different): no analysis carried out, but TTS assumed to be different to control value.

\begin{tabular}{|c|c|c|c|c|c|c|c|c|c|}
\hline \multirow{2}{*}{$\begin{array}{l}\text { SEL } \\
\mathrm{dB} \text { re } 1 \mu \mathrm{Pa}^{2} \mathrm{~s}\end{array}$} & \multirow{2}{*}{$\begin{array}{c}\text { Hearing frequency } \\
\mathrm{kHz}\end{array}$} & \multicolumn{4}{|c|}{ Seal F02, TTS $_{1-4}$ (in dB) } & \multicolumn{4}{|c|}{ Seal F01, TTS $_{12-16}($ in $\mathrm{dB})$} \\
\hline & & $\begin{array}{l}\text { Mean } \\
\mathrm{TTS}_{1-4}\end{array}$ & $\pm \mathrm{SD}$ & Range & $\mathrm{n}$ & $\begin{array}{c}\text { Mean } \\
\text { TTS }_{12-16}\end{array}$ & $\pm \mathrm{SD}$ & Range & $\mathrm{n}$ \\
\hline Control & 6.5 & -0.6 & 1.5 & $-2.3-1.6$ & 6 & 0.3 & 1.8 & $-2.0-2.9$ & 7 \\
\hline 159 & 6.5 & $1.5^{\mathrm{AS}}$ & 1.1 & $0.7-2.3$ & 2 & $0.5^{\mathrm{AS}}$ & - & 0 & 1 \\
\hline 165 & 6.5 & $1.9^{\mathrm{NS}}$ & 1.9 & $0.2-4.2$ & 4 & $4.0 *$ & 1.3 & $2.4-5.6$ & 4 \\
\hline 171 & 6.5 & $1.6^{\mathrm{NS}}$ & 1.9 & $-1.3-3.8$ & 8 & $4.5^{*}$ & 1.8 & $2.4-6.7$ & 7 \\
\hline 177 & 6.5 & $4.3^{*}$ & 1.3 & $2.4-5.8$ & 7 & $4.7 *$ & 1.3 & $3.1-6.2$ & 5 \\
\hline 183 & 6.5 & $3.9 *$ & 0.8 & $2.5-4.7$ & 6 & $5.7 *$ & 2.4 & $2.4-9.2$ & 7 \\
\hline 189 & 6.5 & $5.6^{*}$ & 1.3 & $3.8-7.3$ & 7 & $4.7 *$ & 0.7 & $3.8-5.6$ & 6 \\
\hline 195 & 6.5 & $6.5^{*}$ & 2.7 & $2.9-10.4$ & 5 & $8.9^{*}$ & 2.3 & $4.7-11.7$ & 6 \\
\hline Control & 9.2 & 0.4 & 1.3 & $-1.9-2.4$ & 8 & 0.5 & 1.5 & $-2.4-1.9$ & 8 \\
\hline 171 & 9.2 & $1.6^{\mathrm{NS}}$ & 1.9 & $-1.4-3.6$ & 7 & $0.4^{\mathrm{NS}}$ & 2.0 & $-2.6-3.7$ & 7 \\
\hline 177 & 9.2 & $2.3^{\mathrm{NS}}$ & 0.9 & $1.0-3.4$ & 7 & $1.6^{\mathrm{NS}}$ & 3.0 & $-3.1-5.8$ & 7 \\
\hline 183 & 9.2 & $9.8 *$ & 3.3 & $5.9-15.4$ & 6 & $4.2 *$ & 1.9 & $1.8-7.4$ & 7 \\
\hline 189 & 9.2 & $18.4 *$ & 4.6 & $10.8-23.7$ & 6 & $8.1^{*}$ & 2.7 & $3.0-11.4$ & 7 \\
\hline 195 & 9.2 & $13.9^{\mathrm{AD}}$ & 1.2 & $13.0-14.8$ & 2 & $14.6^{*}$ & 0.0 & $14.6-14.6$ & 2 \\
\hline Control & 13 & 0.2 & 1.3 & $-1.4-2.4$ & 6 & -0.1 & 0.3 & $-0.5-0.2$ & 4 \\
\hline 177 & 13 & $0.1^{\text {AS }}$ & - & 0 & 1 & $0.0^{\mathrm{AS}}$ & - & 0 & 1 \\
\hline 189 & 13 & $1.5^{\mathrm{AS}}$ & - & 0 & 1 & $4.4^{\mathrm{AD}}$ & - & 0 & 1 \\
\hline
\end{tabular}

a correct signal-absence response) in the pre-exposure, postexposure, and control hearing tests were similar (Table II).

\section{Effect of SEL on TTS and recovery time}

The ANOVAs showed that both $\mathrm{TTS}_{1-4}$ (seal F02) and TTS $_{12-16}$ (seal F01) were significantly affected by the fatiguing sound's SEL. Comparisons with the control revealed that the statistically significant onset of TTS varied depending on the animal and the hearing test frequency (Table III).

\section{Seal F02}

With a hearing test signal of $6.5 \mathrm{kHz}$, statistically significant TTS $_{1-4}$ occurred in seal F02 after exposure to an SEL of $177 \mathrm{~dB}$ re $1 \mu \mathrm{Pa}^{2}$ s [Table III; Fig. 3(a)]; hearing recovered within $60 \mathrm{~min}$ [Fig. 4(a)]. With a hearing test signal of $9.2 \mathrm{kHz}$, statistically significant $\mathrm{TTS}_{1-4}$ occurred after exposure to an SEL of $183 \mathrm{~dB}$ re $1 \mu \mathrm{Pa}^{2}$ s [Table III; Fig. 3(a)]. The rate of increase in TTS with increasing SEL (hearing test signal of $9.2 \mathrm{kHz}$ ) was $1.3 \mathrm{~dB} / \mathrm{dB}$ fatiguing sound between 177 and $189 \mathrm{~dB}$ SEL; mean TTS after exposure to $195 \mathrm{~dB}$ re $1 \mu \mathrm{Pa}^{2} \mathrm{~s}$ was $4.5 \mathrm{~dB}$ lower than after exposure to $189 \mathrm{~dB}$ re $1 \mu \mathrm{Pa}^{2}$ s (Table III). Recovery of hearing occurred within $60 \mathrm{~min}$ for exposures up to an SEL of $177 \mathrm{~dB}$ re $1 \mu \mathrm{Pa}^{2} \mathrm{~s}$, and within $24 \mathrm{~h}(1440 \mathrm{~min})$ for SELs of 183 and $195 \mathrm{~dB}$ re $1 \mu \mathrm{Pa}^{2} \mathrm{~s}$ [Fig. 4(b)]. Hearing took more than $24 \mathrm{~h}$ $\left(1440 \mathrm{~min}\right.$ ) to recover after exposure to $189 \mathrm{~dB}$ re $1 \mu \mathrm{Pa}^{2} \mathrm{~s}$. The exact recovery time is not known, as hearing was not measured between 24 and $48 \mathrm{~h}$ after exposure, but $48 \mathrm{~h}$ after exposure, hearing had recovered [not shown in Fig. 4(b)]. Hearing recovery rates at $9.2 \mathrm{kHz}$ varied between 0.05 and $0.13 \mathrm{~dB} / \mathrm{min}$. With a hearing test signal of $13 \mathrm{kHz}$, no TTS $\mathrm{T}_{1-4}$
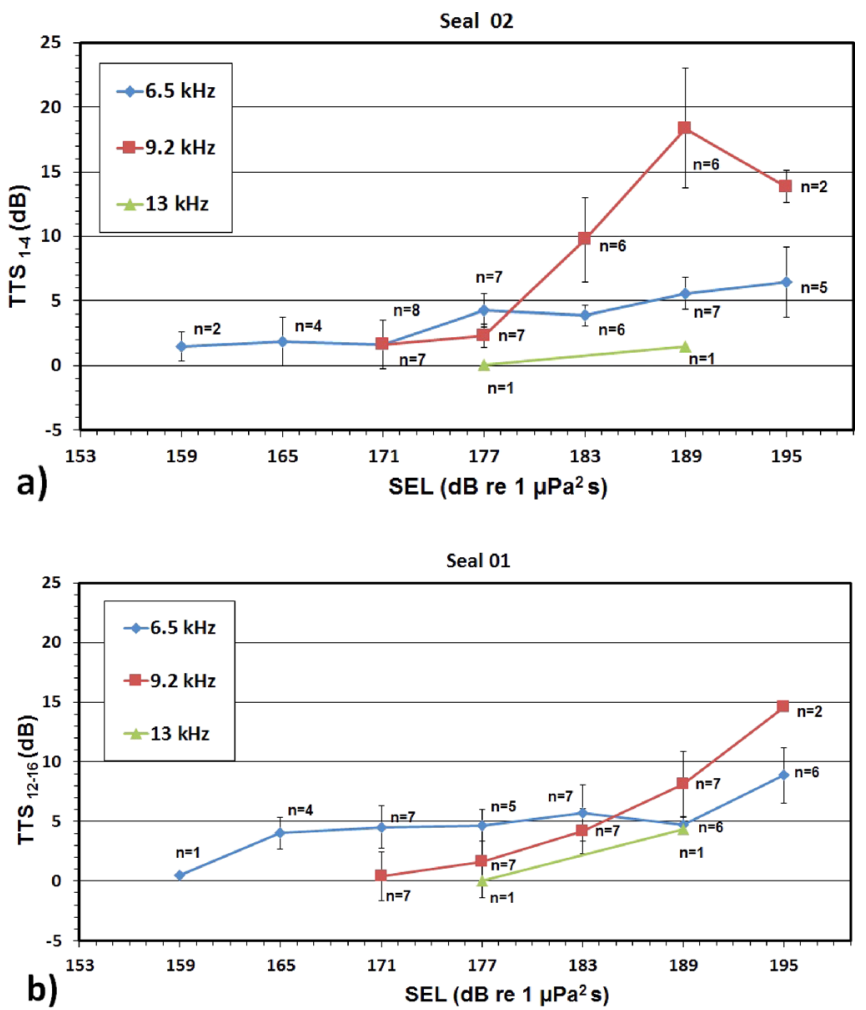

FIG. 3. (Color online) $\mathrm{TTS}_{1-4}$ in seal F02 (a) and TTS T2-16 $_{16}$ in seal F01 (b) after exposure for $60 \mathrm{~min}$ to a continuous tone of $6.5 \mathrm{kHz}$ at several SELs, quantified at hearing frequencies $6.5,9.2$, and $13 \mathrm{kHz}$ (i.e., at $0,0.5$, and 1 octave above the frequency of the fatiguing sound). Sample size (n) varies per data point shown. For SPL (dB re $1 \mu \mathrm{Pa}$ ), subtract $36 \mathrm{~dB}$ re $1 \mathrm{~s}$ from the SEL values. For control values, see Figs. 4 and 5. 


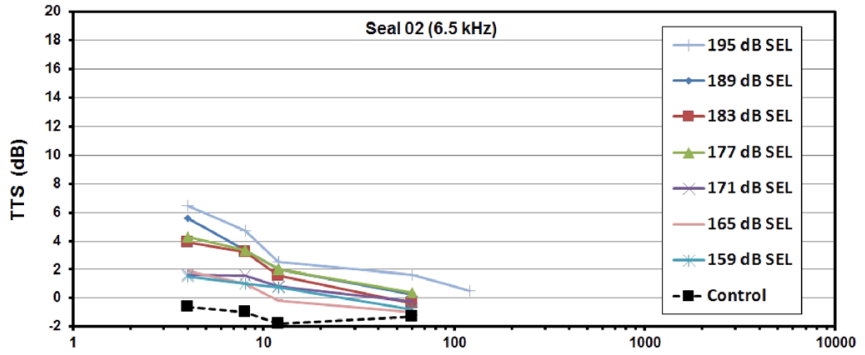

a)

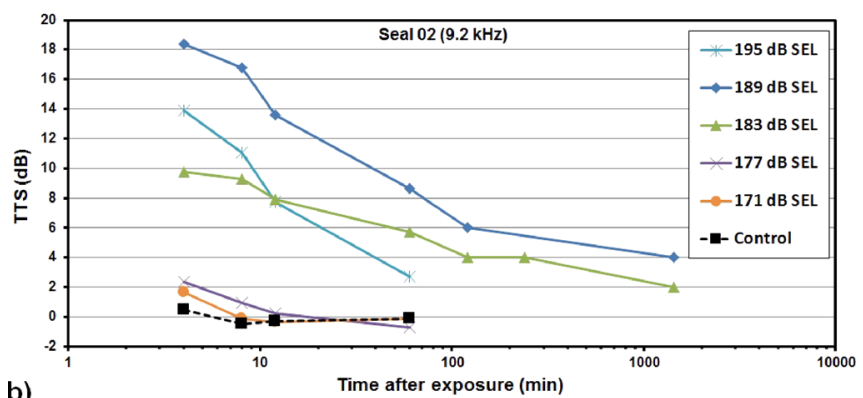

b)

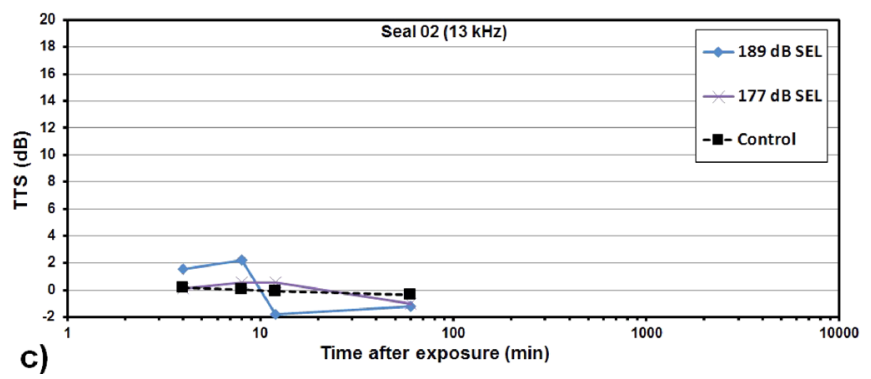

FIG. 4. (Color online) Recovery of the hearing of seal F02 at $6.5 \mathrm{kHz}$ (a), $9.2 \mathrm{kHz}$ (b), and $13 \mathrm{kHz}$ (c), after exposure to a continuous $6.5 \mathrm{kHz}$ tone for $60 \mathrm{~min}$ at several SELs. Mean TTSs are shown. For sample sizes and SDs (only for TTS $_{1-4}$ ), see Table III and Fig. 3. For average received SPLs (dB re $1 \mu \mathrm{Pa}$ ), subtract $36 \mathrm{~dB}$ re $1 \mathrm{~s}$ from the SEL values. Also shown are the TTS values during control sessions.

appeared to occur even after exposure to an SEL of $189 \mathrm{~dB}$ re $1 \mu \mathrm{Pa}^{2}$ s [Table III; Fig. 3(a)]. The control sessions showed that the hearing thresholds for all three hearing test signals before and after $60 \mathrm{~min}$ exposure to low ambient noise were very similar (Fig. 4, Table III).

\section{Seal F01}

With a hearing test signal of $6.5 \mathrm{kHz}$, statistically significant TTS $_{12-16}$ occurred in seal F01 after exposure to an SEL of $165 \mathrm{~dB}$ re $1 \mu \mathrm{Pa}^{2}$ s [Table III; Fig. 3(b)]; hearing recovered within $2 \mathrm{~h}$ [Fig. 5(a)]. With a hearing test signal of $9.2 \mathrm{kHz}$, statistically significant $\mathrm{TTS}_{12-16}$ occurred after exposure to an SEL of $183 \mathrm{~dB}$ re $1 \mu \mathrm{Pa}^{2}$ s [Table III; Fig. 3(b)]. Recovery of hearing occurred within $120 \mathrm{~min}$ for exposures up to SELs of $183 \mathrm{~dB}$ re $1 \mu \mathrm{Pa}^{2}$ s, within 240 min for an SEL of $189 \mathrm{~dB}$ re $1 \mu \mathrm{Pa}^{2} \mathrm{~s}$ and within $24 \mathrm{~h}(1440 \mathrm{~min})$ for an SEL of $195 \mathrm{~dB}$ re $1 \mu \mathrm{Pa}^{2} \mathrm{~s}$ [Fig. 5(b)]. Her hearing recovery rate at $9.2 \mathrm{kHz}$ was around $0.3 \mathrm{~dB} / \mathrm{min}$. With a hearing test signal of $13 \mathrm{kHz}$, TTS $_{12-16}$ appeared to occur at an SEL of $189 \mathrm{~dB}$ re $1 \mu \mathrm{Pa}^{2} \mathrm{~s}$ [Table II; Fig. 3(b)]. Recovery of hearing was within $12 \mathrm{~min}$. The control sessions showed that the hearing thresholds for all three hearing test signals before and after $60 \mathrm{~min}$ exposure to low ambient noise were very similar (Fig. 5, Table III).
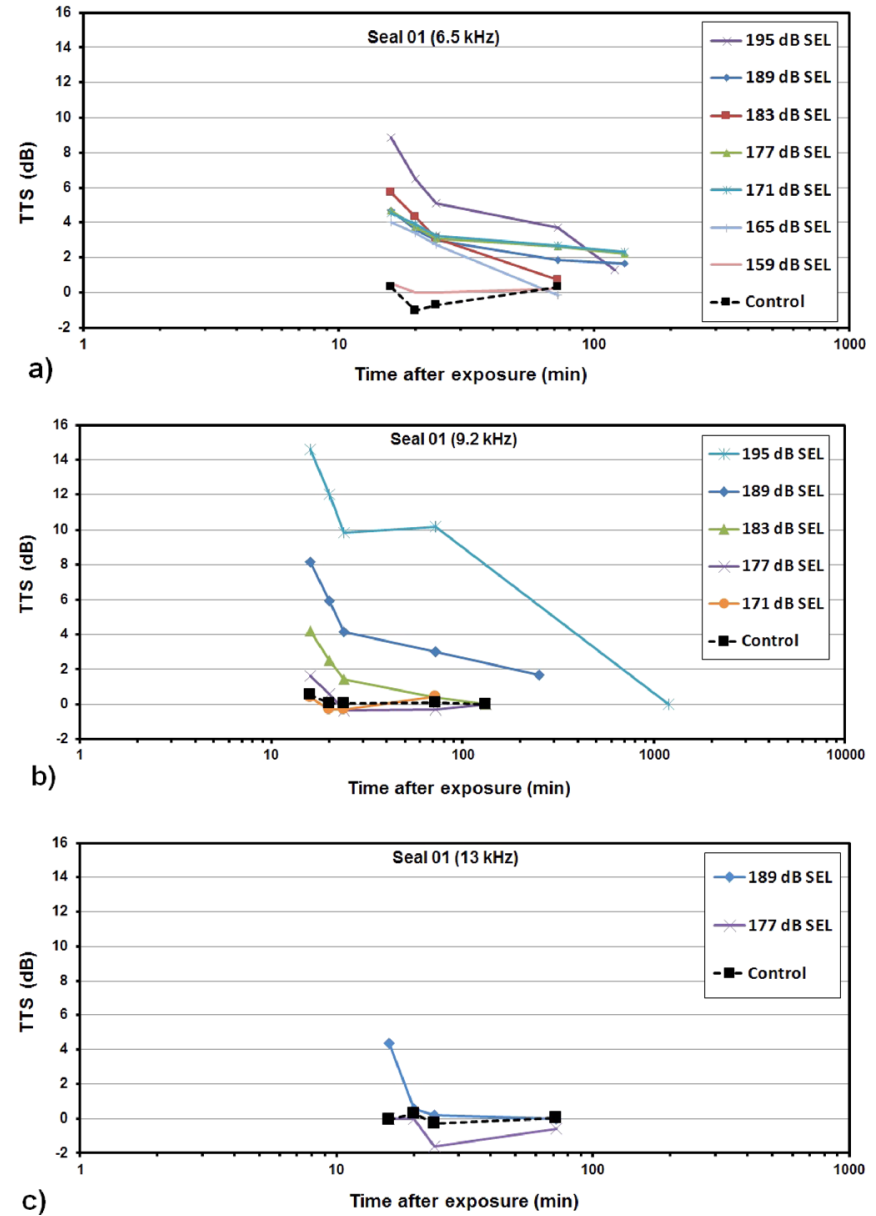

FIG. 5. (Color online) Recovery of the hearing of seal F01 at $6.5 \mathrm{kHz}$ (a), $9.2 \mathrm{kHz}$ (b), and $13 \mathrm{kHz}$ (c), after exposure to a continuous $6.5 \mathrm{kHz}$ tone for $60 \mathrm{~min}$ at several SELs. Mean TTSs are shown. For sample sizes and SDs (TTS $_{12-16}$ only), see Table III and Fig. 3(b). For average received SPLs (dB re $1 \mu \mathrm{Pa}$ ), subtract $36 \mathrm{~dB}$ re $1 \mathrm{~s}$ from the SEL values. Also shown are the TTS values during control sessions.

\section{DISCUSSION AND CONCLUSIONS}

\section{A. Evaluation}

The animals in the present study had normal hearing for young female harbor seals (Kastelein et al., 2018a). The preexposure hearing thresholds found in the present study for the three hearing test signals were within a few $\mathrm{dB}$ of the hearing thresholds measured in these harbor seals for tonal signals during two previous studies (Kastelein et al., 2009a; Kastelein et al., 2010b).

Although the hearing of seal F02 was always tested before the hearing of seal F01, the sound-induced TTS can

TABLE IV. Comparison of mean TTS measured at $9.2 \mathrm{kHz}$ in seal F02 8-12 min after the fatiguing sound stopped, and in seal F01 12-16 min after the fatiguing sound stopped.

\begin{tabular}{lcc}
\hline \hline $\begin{array}{l}\text { SEL } \\
\mathrm{dB} \text { re } 1 \mu \mathrm{Pa}^{2} \mathrm{~s}\end{array}$ & $\begin{array}{c}\mathrm{TTS}_{8-12} \text { in seal F02 } \\
\mathrm{dB}\end{array}$ & $\begin{array}{c}\text { TTS }_{12-16} \text { in seal F01 } \\
\mathrm{dB}\end{array}$ \\
\hline 183 & 8 & 4 \\
189 & 13 & 8 \\
195 & 8 & 15 \\
\hline
\end{tabular}


be compared. The closest possible comparison is of TTS in seal F02 8-12 min and in seal F01 12-16 min after the fatiguing sound stopped. Comparing the recovery of both animals with hearing test signals of $9.2 \mathrm{kHz}$ after exposure to the three highest SELs [Figs. 4(b) and 5(b) and Table IV] shows that the TTS was lower in seal F01 than in seal F02 in two cases (as expected, as seal F02's hearing had had more time to recover). However, at the highest exposure level, TTS was $7 \mathrm{~dB}$ higher in seal F01 than in seal F02. Studies on humans and other terrestrial mammals show large individual, genetic and population-level differences in susceptibility to TTS (Kylin, 1960; Kryter et al., 1962; Henderson et al., 1993; Davis et al., 2003; Spankovich et al., 2014). Therefore, further replication with more harbor seals is needed to assess the generality of the results obtained.

The mean pre-stimulus response rates in hearing tests before and after the sound exposures and during the control sessions were of similar magnitudes in both animals (Table II). This indicates that the seals used the same decision criteria in all conditions, and that their decision-making process in the post exposure hearing tests was not influenced by the sound exposure.

No change in the seals' susceptibility to TTS was observed over time during the present study. The TTSs were less severe than those elicited in studies on terrestrial mammals in which susceptibility to TTS did change due to conditioning (Kujawa and Liberman, 1997; Mannström et al., 2015).

No aerial sound was projected during exposure sessions, based on results from a noise-band study in which the same $\mathrm{TTS}_{1-4}$ was found in harbor seals with and without aerial fatiguing sound in addition to the same underwater fatiguing sound (Kastelein et al., 2012). Harbor seals' hearing thresholds for underwater sounds are the same when they are swimming with their heads at the water surface (nose in the air, mandible and lower part of skull under water) as when they are fully submerged (Kastelein et al., 2018a). However, the seals in the present study spent more time swimming at the water surface during exposure to the $6.5 \mathrm{kHz}$ continuous tone than during the control periods. In addition, the percentage of time swimming at the water surface increased at the two highest SPLs (Table I). A similar phenomenon was seen in the same seals in response to pile driving sounds (Kastelein et al., 2018b). The animals in the present study may have spent time with their heads at the water surface in an attempt to reduce the received level.

Significant TTS as reported in the present study means that statistically significant TTS occurred in the hearing of the study animals (relative to the control sessions). This is not the same as ecologically significant TTS, and it is unclear what the specific ecological effect of TTS is. The ecological effect certainly depends on the magnitude of the TTS, the duration of the exposure (because TTS can begin to occur during exposure), the duration of the recovery of hearing, and the affected hearing frequency. Reduced hearing in seals may reduce the efficiency of ecologically important activities such as navigation, communication, foraging, and predator avoidance, thus potentially reducing their fitness, reproductive output and longevity.

\section{B. Recovery}

There were differences in recovery rates of hearing between the two seals. Seal F02 showed hearing recovery rates varying between 0.05 and $0.13 \mathrm{~dB} / \mathrm{min}$. Seal F01 showed a much stronger initial recovery $(0.3 \mathrm{~dB} / \mathrm{min})$ than seal F02. All TTSs up to $6 \mathrm{~dB}$ recovered within $2 \mathrm{~h}$, most within $1 \mathrm{~h}$. In seal F02, TTS of around $19 \mathrm{~dB}$ recovered within $24 \mathrm{~h}$. The results of the present study and studies by Kastelein et al. (2012) and Kastelein et al. (2018b) suggest that in harbor seals, similar TTSs, caused by different fatiguing sounds (one octave continuous noise band, intermittent impulsive sounds, and a CW) with different exposure levels and exposure times, require similar recovery times.

\section{Hearing frequency most affected}

The results from the present study show that, after they were exposed to a $6.5 \mathrm{kHz} \mathrm{CW}$, the harbor seals suffered TTSs at $6.5,9.2$, and $13 \mathrm{kHz}$, and that the hearing frequency at which the greatest TTS occurred depended on the SPL, and the most affected frequency at high SPLs was half an octave higher $(9.2 \mathrm{kHz})$ than the center frequency of the fatiguing sound $(6.5 \mathrm{kHz})$. TTS research in terrestrial mammals also suggests that the maximum TTS is induced half an octave above the fatiguing sound's frequency (Cody and Johnstone, 1981; McFadden and Plattsmier, 1983; McFadden, 1986), and that the magnitude of TTS induced at frequencies higher than the fatiguing sound's frequency is related to the SPL of the fatiguing sound. Cody and Johnstone (1981) found TTS/SPL curves for guinea pigs to be much steeper for frequencies $\geq 0.5$ octave above the fatiguing sound's frequency than for frequencies $<0.5$ octave above that of the fatiguing sound.

In marine mammals, the relationship between received SPL and affected hearing frequency has so far only been studied in one odontocete species (Kastelein et al., 2015a); after exposure for $60 \mathrm{~min}$ to a $6.5 \mathrm{kHz}$ continuous tone (the same fatiguing sound used in the present study) at SPLs $s_{\text {av.re. }}$ ranging from 118 to $154 \mathrm{~dB}$ re $1 \mu \mathrm{Pa}$, the TTSs of a harbor porpoise were quantified at the center frequency $(6.5 \mathrm{kHz})$, at $0.5(9.2 \mathrm{kHz}), 1.0(13 \mathrm{kHz})$, and 1.3 octaves $(16 \mathrm{kHz})$ above the center frequency of the fatiguing sound. As in the harbor seals, the hearing frequency at which the maximum TTS occurred in the harbor porpoise depended on the $\mathrm{SPL}_{\text {av.re }}$. The higher the $\mathrm{SPL}_{\text {av.re. }}$, the higher the TTS induced at frequencies higher than the frequency of the fatiguing sound; below $148 \mathrm{~dB}$ re $1 \mu \mathrm{Pa}$, the maximum TTS was at $6.5 \mathrm{kHz}$, whereas above $148 \mathrm{~dB}$ re $1 \mu \mathrm{Pa}$, the maximum TTS occurred at $9.2 \mathrm{kHz}$.

The results from the previous studies should be taken into consideration when interpreting studies of TTS in pinnipeds (Finneran et al., 2003; Kastak et al., 1999; Kastak et al., 2005, 2007; Kastak and Schusterman, 1996; Kastelein et al., 2012; Kastelein et al., 2013a; Kastelein et al., 2015b). In some studies, hearing may have been quantified at a frequency that did not show the maximum TTS elicited by the fatiguing sound. When TTS data from previous studies are used for regulatory purposes, the received SPL should be 
taken into account to determine the affected hearing frequency, to evaluate the potential effect of anthropogenic sounds on pinniped hearing, and to assess the ecological impact of the sounds.

\section{Susceptibility to TTS in relation to the frequency of the fatiguing sound}

Based on the presently available data on TTS caused by underwater sound in harbor seals (Kastak et al., 2005, Kastelein et al., 2012, and the present study), their susceptibility to TTS in the fatiguing sound frequency range tested $(2.5-6.5 \mathrm{kHz})$ varies little with hearing frequency (Fig. 6). Kastak et al. (2005) did not specify how soon after the sound (octave-band noise centered at $2500 \mathrm{~Hz}$ ) stopped, or for how long, they tested the hearing (at $2500 \mathrm{~Hz}$ ) of the seal, so recovery before and during the post-exposure hearing tests cannot be evaluated, but in the study by Kastelein et al. (2012) and in the present study (using the same seals), the hearing measurement moments and periods were precisely specified. In the present study, the $\mathrm{SEL}_{\text {cum }}$ required to elicit $6 \mathrm{~dB}$ TTS 1-4 min after the sound exposure stopped at $9.2 \mathrm{kHz}$ was $\sim 180 \mathrm{~dB}$ re $1 \mu \mathrm{Pa}^{2} \mathrm{~s}$ in seal F02 [Fig. 3(a)]; for $6 \mathrm{~dB}$ TTS 12-16 min after the sound exposure stopped (thus after eight more minutes of recovery) it was $\sim 186 \mathrm{~dB}$ re $1 \mu \mathrm{Pa}^{2} \mathrm{~s}$ in seal F01 [Fig. 3(b)]. Thus, the two harbor seals in the present study seem to have similar susceptibility to TTS in the frequency range within which their hearing was tested, and the seal studied by Kastak et al. (2005) also appears to have similar susceptibility to TTS in this range. In the frequency range in which TTS has been tested in harbor seals, the hearing thresholds of the seals are very similar (Kastelein et al., 2009a, 2009b; Fig. 6). More fatiguing sound frequencies need to be tested in harbor seals in order to produce equal TTS curves, on which weighting functions can be based that can be used to set safety criteria for broadband sounds in the marine environment (Houser et al., 2017).

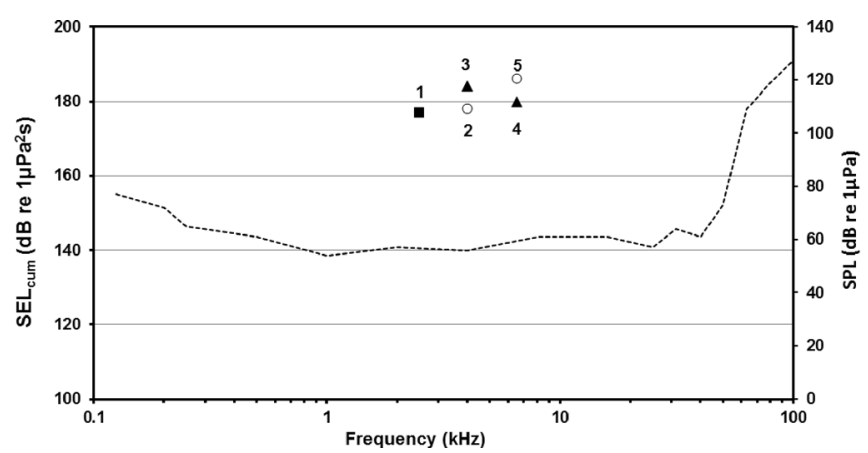

FIG. 6. The $\mathrm{SEL}_{\text {cum }}$ required to cause $6 \mathrm{~dB}$ TTS in harbor seals after exposure to octave-band noise (OBN) centered at $2.5 \mathrm{kHz}$ (Kastak et al., 2005, no.1, male), OBN centered at $4 \mathrm{kHz}$ (Kastelein et al., 2012, $\bigcirc$ no. 2: F01 measured 1-4 min after sound stopped, $\boldsymbol{\Delta}$ no. 3: F02 measured 12-16 min after the sound stopped), and the $\mathrm{CW}$ of $6.5 \mathrm{kHz}$ (present study, no. 4: F02 measured 1-4 min after the sound stopped, no. 5: F01 measured 12-16 min after the sound stopped). Also shown is the mean audiogram of the seals of the present study for tonal signals (right-hand y-axis, dashed line; Kastelein et al., 2009a).

\section{E. Comparison of susceptibility to TTS in phocids and odontocetes}

In a study on TTS in a harbor porpoise, Kastelein et al. (2014b) used the same sound $(6.5 \mathrm{kHz} \mathrm{CW})$ and methodology as used in the present study, so these studies can be compared directly. At $6.5 \mathrm{kHz}$, the porpoise showed $\mathrm{TTS}_{1-4}$ onset (defined as $6 \mathrm{~dB}$ TTS) at $158 \mathrm{~dB}$ SEL, and harbor seal F02 at $189 \mathrm{~dB}$ SEL. At $9.2 \mathrm{kHz}$, the porpoise showed $\mathrm{TTS}_{1-4}$ onset at $176 \mathrm{~dB}$ SEL and seal 02 at $180 \mathrm{~dB}$. Thus it appears (based on very small sample sizes) that the harbor porpoise is more susceptible to TTS (i.e., TTS occurs at lower SELs) due to a $6.5 \mathrm{kHz} \mathrm{CW}$ than the harbor seal. A similar difference in susceptibility to TTS between odontocetes and pinnipeds was shown in a review of TTS and PTS literature by Finneran (2015). The SEL at which the most affected hearing frequency changed from the center frequency of the fatiguing sound to half an octave above it was $184 \mathrm{~dB}$ SEL in the harbor porpoise and $179 \mathrm{~dB}$ SEL in harbor seal F02. This is a small difference, taking into account individual differences in susceptibility to TTS that are likely to occur in both species.

\section{ACKNOWLEDGMENTS}

We thank research assistants Shirley Van de Voorde, Jesse Dijkhuizen, students Ruben de Vos, Danisja Nijsten, Yoni Trienes, Dominique Janssen, Rick van 't Hof, Iris Keurntjes, Simone Winter, Susan Jansen, Thaana van Dessel, and volunteers Aimee van Kommeren, Katja van Rennes, Celine van Putten, Fransien Moerland, Naomi Claeys, Tina Scheers, Jennifer Covi, Stacey van der Linden, Rowanne Huisman, Léonie Huijser, Ruby van Kester, and Brigitte Slingerland for their help in collecting the data. We thank Arie Smink for the design, construction, and maintenance of the electronic equipment. We thank Bert Meijering (Topsy Baits) for providing space for the SEAMARCO Research Institute. Erwin Jansen (TNO) conducted the acoustic calibration measurements. We also thank Nancy Jennings (Dotmoth.co.uk) and Christ de Jong (TNO) for their valuable constructive comments on this manuscript. Funding for this project was obtained from the U.S. Navy's Living Marine Resources program (Contract No. N39430-18-R-2041). We thank Mandy Shoemaker and Anu Kumar for their guidance on behalf of the LMR program. The seals were made available for the research by Ecomare. The training and testing of the harbor seals was conducted under authorization of the Netherlands Ministry of Economic Affairs, Department of Nature Management, with Endangered Species Permit No. FF/75A/2016/031.

ANSI (2013). American National Standard S 1.1-2013, "Acoustical Terminology" (American National Standards Institute, New York).

Burns, J. J. (2002). "Harbor seal and spotted seal," in Encyclopedia of Marine Mammals, edited by W. F. Perrin, B. Würsig, and J. G. M. Thewissen (Academic, San Diego), pp. 552-560.

Carder, H. M., and Miller, J. D. (1972). "Temporary threshold shifts from prolonged exposure to noise," J. Speech Hear. Res. 15, 603-623.

Cody, A. R., and Johnstone, B. M. (1981). "Acoustic trauma: Single neuron basis of the "half-octave shift," "J. Acoust. Soc. Am. 70, 707-711.

Cornsweet, T. N. (1962). "The staircase-method in psychophysics," Am. J. Psychol. 75, 485-491. 
Davis, R. R., Kozel, P., and Erway, L. C. (2003). "Genetic influences in individual susceptibility to noise: A review," Noise Health 5, 19-28.

Finneran, J. J. (2015). "Noise-induced hearing loss in marine mammals: A review of temporary threshold shift studies from 1996-2015," J. Acoust. Soc. Am. 138, 1702-1726.

Finneran, J. J., R. Dear, D. A. Carder, and S. H. Ridgway (2003). “Auditory and behavioral responses of California sea lions (Zalophus californianus) to single underwater impulses from an arc-gap transducer," J. Acoust. Soc. Am. 114, 1667-1677.

Finneran, J. J., and Schlundt, C. E. (2007). "Underwater sound pressure variation and bottlenose dolphin (Tursiops truncatus) hearing thresholds in a small pool," J. Acoust. Soc. Am. 122, 606-614.

Henderson, D., Subramaniam, M., and Boettcher, F. A. (1993). "Individual susceptibility to noise-induced hearing loss: An old topic revisited," Ear Hear. 14,152-168.

Houser, D. S., Yost, W., Burkard, R., Finneran, J. J., Reichmuth, C., and Mulsow, J. (2017). "A review of the history, development and application of auditory weighting functions in humans and marine mammals," J. Acoust. Soc. Am. 141, 1371-1413.

Kastak, D., Reichmuth, C., Holt, M. M., Mulsow, J., Southall, B. L., and Schusterman, R. J. (2007). "Onset, growth, and recovery of in-air temporary threshold shift in a California sea lion (Zalophus californianus)," J. Acoust. Soc. Am. 122, 2916-2924.

Kastak, D., and Schusterman, R. J. (1996). "Temporary threshold shift in a harbor seal (Phoca vitulina)," J. Acoust. Soc. Am. 100, 1905-1908.

Kastak, D., Schusterman, R. J., Southall, B. L., and Reichmuth, C. J. (1999). "Underwater temporary threshold shift induced by octave-band noise in three species of pinniped," J. Acoust. Soc. Am. 106, 1142-1148.

Kastak, D., Southall, B. L., Schusterman, R. J., and Reichmuth Kastak, C. (2005). "Underwater temporary threshold shift in pinnipeds: Effects of noise level and duration," J. Acoust. Soc. Am. 118, 354-3163.

Kastelein, R. A., Gransier, R., and Hoek, L. (2013a). "Comparative temporary threshold shifts in a harbor porpoise and harbor seal, and severe shift in a seal (L)," J. Acoust. Soc. Am. 134(1), 13-16.

Kastelein, R. A., Gransier, R., Hoek, L., Macleod, A., and Terhune, J. M. (2012). "Hearing threshold shifts and recovery in harbor seals (Phoca vitulina) after octave-band noise exposure at $4 \mathrm{kHz}$, , J. Acoust. Soc. Am. 132, 2745-2761.

Kastelein, R. A., Gransier, R., Marijt, M. A. T., and Hoek, L. (2015a). "Hearing frequencies of a harbor porpoise (Phocoena phocoena) temporarily affected by played back offshore pile driving sounds," J. Acoust. Soc. Am. 137, 556-564.

Kastelein, R. A., Helder-Hoek, L., Gransier, R., Terhune, J. M., Jennings, N., and de Jong, C. A. F. (2015b). "Hearing thresholds of harbor seals (Phoca vitulina) for playbacks of seal scarer signals, and effects of the signals on behavior," Hydrobiologia 756, 75-88.

Kastelein, R. A., Helder-Hoek, L., and Terhune, J. M. (2018a). "Hearing thresholds, for underwater sounds, of harbor seals (Phoca vitulina) at the water surface," J. Acoust. Soc. Am. 143, 2554-2563.

Kastelein, R. A., Hoek, L., de Jong, C. A. F., and Wensveen, P. J. (2010a). "The effect of signal duration on the underwater detection thresholds of a harbor porpoise (Phocoena phocoena) for single frequency-modulated tonal signals between 0.25 and $160 \mathrm{kHz}$," J. Acoust. Soc. Am. 128, 3211-3222.

Kastelein, R. A., Hoek, L., Gransier, R., and Jennings, N. (2013b). "Hearing thresholds of two harbor seals (Phoca vitulina) for playbacks of multiple pile driving strike sounds," J. Acoust. Soc. Am. 134, 2307-2312.

Kastelein, R. A., Hoek, L., Gransier, R., Rambags, M., and Claeys, N. (2014a). "Effect of level, duration, and inter-pulse interval of $1-2 \mathrm{kHz}$ sonar signal exposures on harbor porpoise hearing," J. Acoust. Soc. Am. 136, 412-422.

Kastelein, R. A., Hoek, L., Kommeren, A., Covi, J., and Gransier, R. (2018b). "Effect of pile driving sounds on harbor seals (Phoca vitulina) hearing," J. Acoust. Soc. 143, 3583-3594.
Kastelein, R. A., Hoek, L., Wensveen, P. J., Terhune, J. M., and de Jong, C. A. F. (2010b). "The effect of signal duration on the underwater hearing thresholds of two harbor seals (Phoca vitulina) for single tonal signals between 0.2 and $40 \mathrm{kHz}$," J. Acoust. Soc. Am. 127, 1135-1145.

Kastelein, R. A., Schop, J., Gransier, R., and Hoek, L. (2014b). "Frequency of greatest temporary hearing threshold shift in harbor porpoises (Phocoena phocoena) depends on the noise level," J. Acoust. Soc. Am. 136, 1410-1418.

Kastelein, R. A., Wensveen, P. J., Hoek, L., and Terhune, J. M. (2009b). "Underwater detection of narrow noise bands between 0.2 and 80 kHz by harbor seals (Phoca vitulina)," J. Acoust. Soc. Am. 126, 476-483.

Kastelein, R. A., Wensveen, P. J., Hoek, L., Verboom, W. C., and Terhune, J. M. (2009a). "Underwater detection of tonal signals between 0.125 and $100 \mathrm{kHz}$ by harbor seals (Phoca vitulina)," J. Acoust. Soc. Am. 125, $1222-1229$.

Kryter, K. D., Weisz, A. Z., and Wiener, F. M. (1962). "Auditory fatigue from audio analgesia," J. Acoust. Soc. Am. 34, 383-391.

Kujawa, S. G., and Liberman, M. C. (1997). "Conditioning-related protection from acoustic injury: Effects of chronic differentation and sham surgery," J. Am. Physiol. Soc. 22, 3095-3106.

Kylin, B. (1960). "Temporary threshold shift and auditory trauma following exposure to steady-state noise," Acta Oto-Laryngol. 51-56(Suppl. 152), $1-94$.

Levitt, H. (1971). "Transformed up-down methods in psychoacoustics," J. Acoust. Soc. Am. 49, 467-477.

Madsen, P. T. (2005). "Marine mammals and noise: Problems with root mean square sound pressure levels for transients," J. Acoust. Soc. Am. 117, 3952-3957.

Mannström, P., Kirkegaard, M., and Ulfendahl, M. (2015). "Repeated moderate noise exposure in the rat-An early adulthood noise exposure model," J. Assoc. Res. Otolaryngol. 16, 763-772.

McFadden, D. (1986). "The curious half octave shift: Evidence for a basalward migration of the traveling-wave envelope with increasing intensity," in Basic and Applied Aspects of Noise-Induced Hearing Loss, edited by R. J. Salvi, D. Henderson, R. P. Hamernik, and V. Colletti (Plenum, New York), pp. 295-312.

McFadden, D., and Plattsmier, H. S. (1983). "Frequency patterns of TTS for different exposure intensities," J. Acoust. Soc. Am. 74, 1178-1184.

Melnick, W. (1991). "Human temporary threshold shifts (TTS) and damage risk," J. Acoust. Soc. Am. 90, 147-154.

Mills, J. H., Gilbert, R. M., and Adkins, W. Y. (1979). "Temporary threshold shift in humans exposed to octave bands of noise for 16 to 24 hours," J. Acoust. Soc. Am. 65, 1238-1248.

Ramamoorthy, S., and Nuttal, A. L. (2012). "Half-octave shift in mammalian hearing is an epiphenomenon of the cochlear amplifier," PLoS One 7, e45640.

Robinson, D. E., and Watson, C. S. (1973). "Psychophysical methods in modern psychoacoustics," in Foundations of Modern Auditory Theory, edited by J. V. Tobias (Academic, New York), Vol. 2, pp. 99-131.

Spankovich, C., Griffiths, S. K., Lobariñas, E., Morgenstein, K. E., de la Calle, S., Ledon, V., Guercio, D., and Le Prell, C. G. (2014). "Temporary threshold shift after impulse-noise during video game play: Laboratory data," Int. J. Audiol. 53, S53-S65.

Supin, A. Y., Popov, V. V., and Mass, A. M. (2001). The Sensory Physiology of Aquatic Mammals (Kluwer Academic, Boston), pp. 205-282.

Wang, Y., Hirose, K., and Liberman, M. C. (2002). "Dynamics of noiseinduced cellular injury and repair in the mouse cochlea," J. Assoc. Res. Otolaryngol. 3, 248-268.

Yost, W. A. (2007). Fundamentals of Hearing: An Introduction (Academic, New York), 326 pp.

Zar, J. H. (1999). Biostatistical Analysis (Prentice-Hall, Upper Saddle River, NJ), $718 \mathrm{pp}$. 